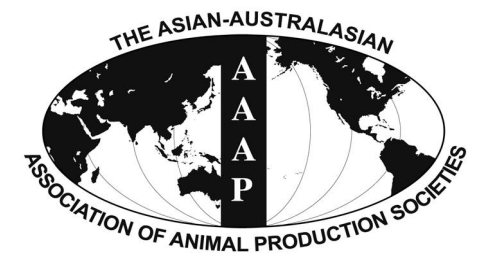

Open Access

Asian Australas. J. Anim. Sci.

Vol. 29, No. 6 : 814-822 June 2016

http://dx.doi.org/10.5713/ajas.15.0414

Www.ajas.info

pISSN 1011-2367 elSSN 1976-5517

\title{
Yeast Culture and Vitamin E Supplementation Alleviates Heat Stress in Dairy Goats
}

\author{
Lizhi Wang ${ }^{1,2}$, Zhisheng Wang ${ }^{1,2}$, Huawei Zou ${ }^{1,2}$, and Quanhui Peng ${ }^{1,2, *}$ \\ ${ }^{1}$ Animal Nutrition Institute, Sichuan Agricultural University, Ya'an 625014, China
}

\begin{abstract}
This study was conducted to determine and compare the effects of yeast yeast culture (YC) and vitamin E (VE) supplementation on endotoxin absorption and antioxidant status in lactating dairy goats suffering from heat stress (HS). Three first lactation Saanen dairy goats (body weight $30 \pm 1.5 \mathrm{~kg}$ ) were surgically fitted with indwelling catheters in the portal vein, mesenteric vein and carotid artery, and were randomly assigned to a $3 \times 3$ Latin square design. Dietary treatments were the basal diet, and the basal diet supplemented with either $100 \mathrm{IU}$ VE or $30 \mathrm{~g} \mathrm{YC}$. Goats were kept in temperature and humidity-controlled room at $35^{\circ} \mathrm{C}$ from 8:00 to 20:00 and at $24^{\circ} \mathrm{C}$ from 20:00 till the next morning at 8:00. The relative humidity was kept at 55\%. HS increased dairy goats' rectum temperature and respiration frequency $(\mathrm{p}<0.01)$. HS reduced plasma flux rate of milk goats $(\mathrm{p}<0.01)$, but the plasma flux rate increased when the animal was under the conditions of the thermo-neutral period $(\mathrm{p}<0.01)$. The VE supplementation lowered dairy goats' rectum temperature during thermo-neutral period $(\mathrm{p}<0.01)$. Meanwhile, no significant differences were observed between the control and YC treatment in rectum temperature and respiration frequency $(\mathrm{p}>0.05)$. Dietary supplementation of VE and YC reduced heat stressed dairy goats' endotoxin concentration of the carotid artery and portal vein $(\mathrm{p}<0.01)$. However, the endotoxin concentration of the YC treatment was higher than that of the VE treatment $(\mathrm{p}<0.01)$. Both VE and YC supplementation decreased heat stressed dairy goats' absorption of endotoxin in portal vein $(\mathrm{p}<0.01)$. The endotoxin absorption of $\mathrm{YC}$ treatment was higher than the $\mathrm{VE}$ treatment $(\mathrm{p}<0.01)$. The addition of VE and YC decreased dairy goats' superoxide dismutase (SOD) concentration during HS and the whole experiment period ( $<<0.01)$. The addition of VE lowered SOD concentration during thermo-neutral period $(\mathrm{p}<0.01)$. Likewise, the addition of VE and YC lowered dairy goats' malonaldehyde (MDA) concentration during HS and the whole experimental period, and the MDA concentration in the VE treatment was lower than the YC treatment $(\mathrm{p}<0.05)$. The addition of VE decreased MDA concentration during thermo-neutral period. On the contrast, the addition of VE increased dairy goats total antioxidant potential (TAP) concentration during HS, thermo-neutral and the whole experimental period $(\mathrm{p}<0.01)$. The addition of $\mathrm{YC}$ increased TAP concentration only during HS period ( $\mathrm{p}<0.01)$. It is concluded that both VE and YC are useful in alleviating HS of dairy goats by weakening endotoxin absorption and promoting antioxidant capacity. Compared with YC, VE is much more powerful in easing dairy goats HS. (Key Words: Dairy Goats, Heat Stress, Vitamin E, Yeast Culture, Endotoxin Absorption)
\end{abstract}

\section{INTRODUCTION}

The gastrointestinal tract of dairy goat presents an extensive surface area providing direct contact between the animal and a large assortment of nutrients, microbes and exogenous toxins. The intestine should permit the exchange of nutrients between the gut lumen and the systemic

\footnotetext{
* Corresponding Author: Quanhui Peng. Tel: +86-152-8351-1570, Fax: +86-835-2885730, E-mail: pengquanhui@126.com

${ }^{2}$ Key Laboratory of Low Carbon Culture and Safety Production in Cattle in Sichuan, Ya'an 625014, China.

Submitted May 9, 2015; Revised Jul. 29, 2015; Accepted Sept. 23, 2015
}

circulation, while preventing penetration of pathogenic organisms and toxic compounds (Marai et al., 2007). However, it had been documented that heat stress (HS) may cause injury to the intestinal epithelium (Bouchama and Knochel, 2002; Fan et al., 2014) which leads to the entrance of bacterial endotoxin into the systemic circulation (Gathiram et al., 1987; Hall et al., 2001; Wang et al., 2011). The entrance of endotoxin in systemic circulation leads to a wide range of injuries including inflammation, damage of internal organs, disseminated intravascular coagulation, and even death (Gathiram et al., 1987; Mani et al., 2012). Therefore, preventing endotoxin absorption during HS may 
be greatly beneficial to animal health. Huber (1998) reported that the supplementation of yeast culture (YC) increased dry matter intake (DMI) and milk production of Holstein cows during HS. However, how YC achieves this effect is still unknown. It was reported that HS reduced the antioxidant capacity by reducing the activity of antioxidant enzymes (Harmon et al., 1997), which increased the amount of free radicals (Flanagan et al., 1998; Pan et al., 2012), and the reduction of the antioxidant capacity was the main cause of injury to the gastrointestinal tract (Hall et al., 2001). On the other hand, vitamin $\mathrm{E}$ (VE) is a proven effective antioxidant. It is well documented VE is active in alleviating poultry HS (Bollengier-Lee et al., 1998; 1999). Although, whether VE alleviates HS in dairy goats is still unknown. Therefore, the objectives of this study were to evaluate and compare the effects of $\mathrm{YC}$ and $\mathrm{VE}$ supplementation on endotoxin absorption and antioxidant status in lactating dairy goats suffering from HS.

\section{MATERIAL AND METHODS}

\section{Animals and surgery}

All experimental procedures involving animals were approved by the Animal Care and Use Committee of Animal Nutrition Institute, Sichuan Agricultural University, and were carried out in accordance with the National Research Council's Guide for the Care and Use of Laboratory Animals.

Three lactating Saanen dairy goats (body weight $30 \pm 1.5$ $\mathrm{kg}$ ) were surgically fitted with indwelling catheters in the portal vein, the mesenteric vein and carotid artery. Portal vein catheters were silicone tube, and the 2 mesenteric catheters were made of Tygon. Two mesenteric venous catheters were inserted into branches between the major venous arch and the small intestine, one for sampling and the other for para-aminohippurate infusion. The establishment of catheters (portal vein and mesenteric vein) was described by Huntington et al. (1989). Surgically peel off the truncus vagosympathicus which is concomitant to the right carotid, and then the carotid was wrapped and sealed in skin by stitch. Carotid catheter was inserted into the dissociative carotid one day before sampling.

\section{Experimental design and feeding management}

The animals were housed in individual metabolic cages in a temperature and humidity-controlled house with ad libitum access to water and were hand milked twice daily. The goats were fed a basal diet during the preliminary period. After a 2 -wk preliminary period the three goats were randomly assigned to a $3 \times 3$ Latin square design. The 3 dietary treatments were basal diet (Control), basal diet supplemented with $100 \mathrm{IU}$ VE, and basal diet supplemented with $30 \mathrm{~g}$ Original XPTM (A kind of YC, the product of
Diamond $\mathrm{V}$ Biological Fermentation Engineering \& Technologies Shenzhen Co., Ltd., Shenzhen, Guangdong, China). Each period lasted 14 days and the animals were fed the experimental diets. During the 2 -wk of each period, the last 4 days were for sample collection. Basal diet was fed twice daily in equal amounts. VE and YC were supplemented at 8:00. The formulation of the basal diet was summarized in Table 1. The room temperature during experiment period was $35^{\circ} \mathrm{C}$ from 8:00 to $20: 00$ and $24^{\circ} \mathrm{C}$ from 20:00 till the next morning at 8:00. The relative humidity kept stable (55\%). Feed intake was recorded daily.

\section{Sampling and analyses}

Each sample collection period last 4 days. On the eleventh day of experiment, a continuous mesenteric venous infusion of para-aminohippurate $(15 \mathrm{mg} / \mathrm{mL}$ formulated according to Huntington [1982]) was initiated via the distal mesenteric vein catheter to determine portal and mesenteric venous blood flows. Continuous infusion was performed by using a HL-2B calibrated syringe pump (Made in Lanngue Instrument Company, Shijiazhuang, China) with a speed of $12 \mathrm{mg}$ para-aminohippurate per $\min (0.8 \mathrm{~mL} / \mathrm{min})$. The infusion commenced at 13:00, $2 \mathrm{~h}$ after which a spot sampling procedure was administrated. A total of 12 spot samplings were performed at $1 \mathrm{~h}$ intervals. At each

Table 1. Ingredients and nutrient content of the basal diet fed to goats

\begin{tabular}{lc}
\hline Items & $\mathrm{g} / 100 \mathrm{~g}$ \\
\hline Ingredients & 50.0 \\
Oat hay & 20.0 \\
Corn & 15.0 \\
Wheat bran & 8.0 \\
Soybean meal & 4.5 \\
Rapeseed meal & 0.8 \\
Calcium carbonate & 0.1 \\
Dicalcium phosphate & 0.5 \\
Salt & 1.0 \\
Sodium bicarbonate & 0.1 \\
Premix & \\
Nutrition level, dry matter basis & \\
NE $(\mathrm{MJ} / \mathrm{kg})$ & 5.52 \\
$\mathrm{CP}(\%)$ & 12.6 \\
Ca $(\%)$ & 0.55 \\
Tp $(\%)$ & 0.32 \\
VE ${ }^{2}(\mathrm{IU} / \mathrm{kg})$ & 28.7 \\
Concentrate/roughage & \\
\hline
\end{tabular}

$\mathrm{NE}_{\mathrm{L}}$, net energy for lactation; $\mathrm{CP}$, crude protein; $\mathrm{Ca}$, Calcium; $\mathrm{Tp}$, total phosphorus; VE, vitamin E.

${ }_{1}^{1}$ Premix contained $\mathrm{FeSO}_{4} \cdot 7 \mathrm{H}_{2} \mathrm{O} 170 \mathrm{~g} / \mathrm{kg} ; \mathrm{CuSO}_{4} \cdot 5 \mathrm{H}_{2} \mathrm{O} \quad 70 \mathrm{~g} / \mathrm{kg}$; $\mathrm{MnSO}_{4} \cdot 5 \mathrm{H}_{2} \mathrm{O} 290 \mathrm{~g} / \mathrm{kg} ; \mathrm{ZnSO}_{4} \cdot 7 \mathrm{H}_{2} \mathrm{O} 240 \mathrm{~g} / \mathrm{kg} ; \mathrm{CoCl}_{2} \cdot 6 \mathrm{H}_{2} \mathrm{O} 510 \mathrm{mg} / \mathrm{kg}$; $\mathrm{KI} 220 \mathrm{mg} / \mathrm{kg} ; \mathrm{Na}_{2} \mathrm{SeO}_{3} 130 \mathrm{mg} / \mathrm{kg}$; vitamin A 1, 620,000 IU/kg; vitamin $\mathrm{D}_{3} 324,000 \mathrm{IU} / \mathrm{kg}$; vitamin E $540 \mathrm{IU} / \mathrm{kg}$.

${ }^{2,3} \mathrm{VE}$ concentration and ratio of concentrate to roughage was determined, and all the other parameters were calculated. 
sampling spot, simultaneous arterial, portal and mesenteric venous blood samples were collected $(5 \mathrm{~mL}$ for each sample) and were slowly dropped into a cuvette containing heparin $(200 \mathrm{IU} / \mathrm{mL})$. Samples were centrifuged at 1,500 rpm for $15 \mathrm{~min}$ at $4^{\circ} \mathrm{C}$. Serum was frozen at $-20^{\circ} \mathrm{C}$ for further analyses.

The para-aminohippurate concentration of plasma was determined according to Huntington (1982). Plasma concentration of superoxide dismutase (SOD), total antioxidant potential (TAP) and malonaldehyde (MDA) were measured using the methods of xanthine oxidation, ferric reducing/antioxidant power, and thiobarbituric acid, respectively. Reagent kits were bought from Jiancheng Bioengineering Institute, Nanjing, China. Plasma endotoxin concentration was determined by kinetic turbidimetric assay (Yokota et al., 1989), using reagent kit bought from Xiamen tachypleus amebocyte lysate Co. LTD, Xiamen, China. The brief description of the procedure is: The standard endotoxin (E. coli 0111: B4) was dissolved in pyrogen-free distilled water. A BECKMAN VIS-723 Spectrophotometer (Beckman Coulter, Inc., Brea, CA, USA) was used and the absorbance of different concentrations of endotoxin dilutions at $545 \mu \mathrm{m}$ were recorded. The absorbance data was used as the ordinate and the endotoxin concentrations as the abscissa to establish standard curve. The plasma samples were pretreated with moderate heating. Then 0.2 $\mathrm{mL}$ pyrogen-free water and $0.2 \mathrm{~mL}$ Tris- $\mathrm{Hcl}$ was added to $0.1 \mathrm{~mL}$ plasma and mixed, the mixture was placed into $100^{\circ} \mathrm{C}$ water bath for $10 \mathrm{~min}$, centrifuged for $10 \mathrm{~min}(3,000$ $\mathrm{rpm}$ ), then $0.1 \mathrm{~mL}$ supernatant was taken for further determination. Next, $0.05 \mathrm{~mL}$ Limulus amebocyte lysate was added to the supernatant and mixed, and the tube placed into $37^{\circ} \mathrm{C}$ water bath for $25 \mathrm{~min}$, and then $0.05 \mathrm{~mL}$ shark tripeptide was added and placed into $37^{\circ} \mathrm{C}$ water bath for $3 \mathrm{~min}$, and $0.05 \mathrm{~mL}$ houjiaruya nitrate solution added and mixed, then $0.5 \mathrm{~mL}$ amino acid amine added and mixed, and finally added $0.5 \mathrm{~mL}$ benzathine. The absorbance of the mixture at $545 \mu \mathrm{m}$ was recorded. The endotoxin concentration could be obtained using the standard curve.

\section{Rectum temperature and respiration frequency}

Rectum temperature and respiration frequency were measured at 16:00, 18:00, 20:00, 22:00, 24:00, 02:00 on the 4 th day of each period. Rectum temperature was measured by inserting thermometer into anus for $3 \mathrm{~cm}$, and respiration frequency was calculated by counting the undulant times of flank within certain time slot measured by stopwatch.

\section{Parameters calculation}

Portal and mesenteric venous blood flows were calculated from the following equations respectively:
Portal blood flows

$=$ Para-aminohippurate infusion rate

/(Para-aminohippurate concentrations in the portal venous blood - Para-aminohippurate concentrations in the arterial blood)

Mesenteric blood flows

$=$ Para-aminohippurate infusion rate

/(Para-aminohippurate concentrations in the mesenteric venous blood - Para-aminohippurate concentrations in the arterial blood )

Net fluxes of endotoxin across portal-and mesentericdrained viscera were calculated from the following equations:

Net absorption of endotoxin via portal-drained viscera

$=$ (concentrations of endotoxin in the portal blood - concentrations of endotoxin in the arterial blood) $\times$ portal blood flow $\times 1,000$

Net absorption of endotoxin via mesenteric-drained viscera $=$ (concentrations of endotoxin in the mesenteric blood - concentrations of endotoxin in the arterial blood) $\times$ mesenteric blood flow $\times 1,000$

Net fluxes of antioxidants (including TAP, SOD, and MDA across portal-and mesenteric-drained viscera were calculated from the following equations:

Net flux of endotoxin via portal-drained viscera $=$ plasma concentrations of antioxidants in the portal blood $\times$ portal blood flow

Net flux of endotoxin via mesenteric-drained viscera

$=$ concentrations of antioxidants in the mesenteric blood $\times$ mesenteric blood flow

\section{Statistical analyses}

The MIXED model $\mathrm{Y}_{\mathrm{ij}}=\mu+\mathrm{T}_{\mathrm{i}}+\mathrm{e}_{\mathrm{ij}}$ of SAS (SAS Institute, 2009) was used to analyze all of the data, where $Y_{i j}$ is an observation on the dependent variable $\mathrm{ij}, \mu$ is the overall population mean, $T_{i}$ is the fixed effect of treatments (VE vs $\mathrm{YC}), \mathrm{e}_{\mathrm{ij}}$ is the random error associated with the observation ij. The data of plasma flux rate, endotoxin concentration in the portal vein and carotid, endotoxin absorption in the portal vein, plasma concentration of SOD, TAP, and MDA across different time spots were also analyzed using the same model, where the $T_{i}$ is the fixed effect of different time spots. When significant differences $(p<0.05)$ were detected, post-hoc analyses were carried out using least significant difference test to compute pairwise differences in the means. Means with different superscript letter groups 
Table 2. Dry mater intake of the goats in different treatments

\begin{tabular}{lccc}
\hline \multirow{2}{*}{ Item } & \multicolumn{3}{c}{ Treatments } \\
\cline { 2 - 4 } & Control & VE & YC \\
\hline DMI $(\mathrm{kg} / \mathrm{d})$ & $1.52 \pm 0.06$ & $1.60 \pm 0.09$ & $1.51 \pm 0.08$ \\
\hline VE
\end{tabular}

VE, vitamin E; YC, yeast culture; DMI, dry matter intake.

were obtained with PDMIX 800 SAS macro (SAS, Cary, $\mathrm{NC}$, USA). Data were presented as mean \pm standard deviation.

\section{RESULTS}

\section{Dry matter intake}

The effect of supplementation YC and VE on the DMI of dairy goats is reported in Table 2 . Feed intake of goats did not differ among treatments during the whole experiment period $(\mathrm{p}=0.402)$.

\section{Rectum temperature and respiration frequency}

Rectum temperature of the goats in the 3 treatments did not differ from each other $(\mathrm{p}=0.125)$ during HS period, and decreased significantly $(\mathrm{p}<0.01)$ when ambient temperature dropped from $35^{\circ} \mathrm{C}$ to $24^{\circ} \mathrm{C}$ (Figure 1a). During thermo-neutral period, rectum temperature of the goats in VE and YC treatments kept on falling. Rectum temperature of the goats in YC treatment did not differ $(\mathrm{p}=$ 0.478 ) from $V E$ treatment from 20:00 to 24:00, but greater $(\mathrm{p}<0.05)$ than VE treatment from 24:00 to 02:00 (Figure 1). Average rectum temperature of the goats during thermoneutral period in the control was similar $(p=0.096)$ as that in YC treatment, and was greater $(p<0.05)$ than VE treatment (Table 3$)$. There was no difference $(p=0.329)$ among the 3 treatments on rectum temperature during HS period and during the whole experiment period (Table 3). Respiration frequency of the goats in the 3 treatments kept stable from 16:00 to 20:00, and dropped significantly $(\mathrm{p}<0.01)$ when ambient temperature decreased from $35^{\circ} \mathrm{C}$ to $24^{\circ} \mathrm{C}$ (Figure 1b). Average respiration frequency of the goats in the 3 treatments during thermo-neutral period $(\mathrm{p}=$

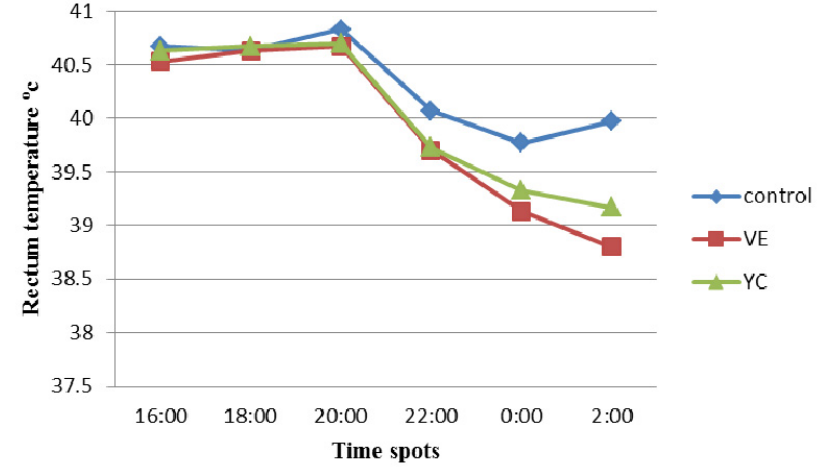

(a)

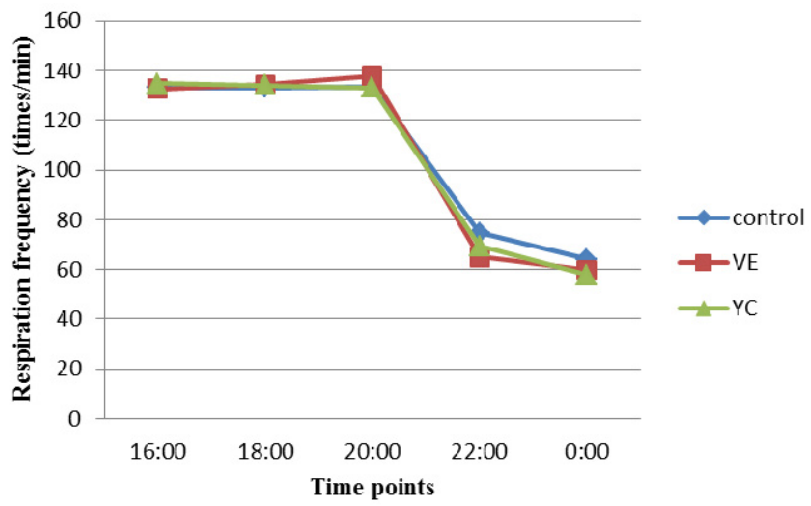

(b)

Figure 1. Rectum temperature (a) and respiration frequency (b) of the goats in different treatments at different time spots. VE, vitamin $\mathrm{E}$; YC, yeast culture.

$0.205)$, HS period $(\mathrm{p}=0.224)$, and the whole experiment period $(\mathrm{p}=0.897)$, was not different from each other (Table 3).

\section{Plasma flux rate}

There was no significant difference $(p>0.05)$ in the rate of plasma flux of the goats among the 3 treatments during HS period (15:00 to 20:00) (Figure 2). However, with the prolonged HS, plasma flux rate in portal vein kept on decreasing. When the ambient temperature decreased from $35^{\circ} \mathrm{C}$ to $24^{\circ} \mathrm{C}$, plasma flux rate of the goats in 3 treatments

Table 3. Average rectum temperature and respiration frequency of the goats in different treatments and in different periods

\begin{tabular}{lccc}
\hline Item & \multicolumn{3}{c}{ Treatments } \\
\cline { 2 - 4 } & Control & VE & YC \\
\hline Rectum temperature $\left({ }^{\circ} \mathrm{C}\right)$ & & & $40.67 \pm 0.02$ \\
$\quad$ Average in heat stress period & $40.72 \pm 0.06$ & $40.61 \pm 0.04$ & $39.41 \pm 0.17^{\mathrm{ab}}$ \\
Average in thermo-neutral period & $39.93 \pm 0.09^{\mathrm{a}}$ & $39.21 \pm 0.26^{\mathrm{b}}$ & $40.04 \pm 0.29$ \\
Average of whole period & $40.33 \pm 0.18$ & $39.91 \pm 0.33$ & $133.89 \pm 0.48$ \\
Respiration frequency (times/min) & & & $60.56 \pm 4.47$ \\
Average in heat stress period & $133.11 \pm 0.11$ & $134.89 \pm 1.47$ & $97.22 \pm 16.52$ \\
Average in thermo-neutral period & $67.67 \pm 3.50$ & $60.11 \pm 2.70$ & $97.50 \pm 16.78$ \\
Average of whole period & $100.39 \pm 14.72$ & &
\end{tabular}

\footnotetext{
VE, vitamin E; YC, yeast culture.
}

${ }^{a, b}$ Means within a row without a similar superscript are different $(p<0.05)$. 


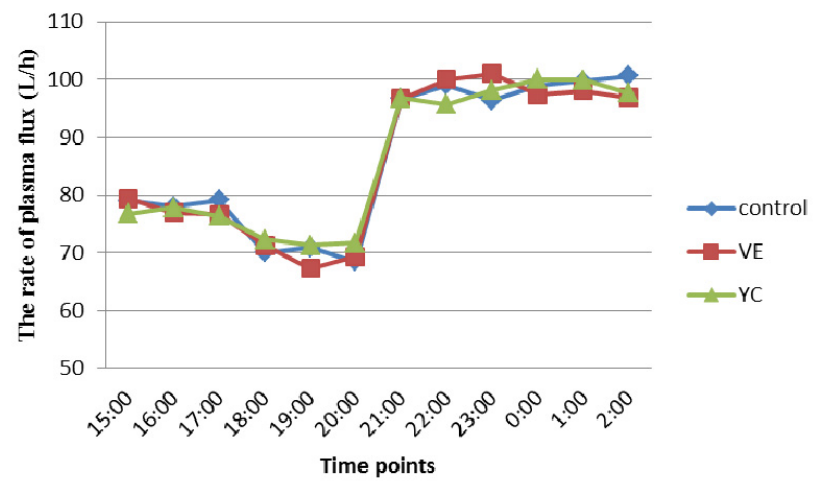

Figure 2. The rate of plasma flux of the goats in different treatments at different time spots. VE, vitamin E; YC, yeast culture.

increased significantly $(p<0.01)$. The average plasma flux rate of the goats did not differ among treatments during thermo-neutral period $(p=0.769)$, HS period $(p=0.717)$, and the whole experiment period $(\mathrm{p}=0.863)($ Table 4$)$.

\section{Endotoxin concentration and absorption}

Endotoxin concentration in the portal vein and carotid of the goats kept stable from 15:00 to 20:00 (HS period) within each treatment, and decreased $(\mathrm{p}<0.01)$ sharply after 21:00 (Figure 3a,b). The endotoxin concentration in the portal vein and carotid of the goats during HS period was the highest in the control $(\mathrm{p}<0.01)$, followed by YC treatment $(\mathrm{p}<0.05)$, and the lowest in VE treatment $(\mathrm{p}<0.01)$. However it was not different during thermo-neutral period $(\mathrm{p}=0.175$ for portal vein, and $\mathrm{p}=0.185$ for carotid) among the 3 treatments (Table 5).

The endotoxin absorption was the highest $(\mathrm{p}<0.01)$ in the control treatment and lowest $(\mathrm{p}<0.01)$ in VE treatment at any time spot (Figure 3c). The maximum absorption of endotoxin in the three treatments happened at 21.00, followed by 22.00 , significantly greater $(\mathrm{p}<0.01)$ than any
Table 4. The rate of plasma flux of the goats in different treatments and in different periods

\begin{tabular}{lccc}
\hline \multirow{2}{*}{ Item } & \multicolumn{3}{c}{ Treatments } \\
\cline { 2 - 4 } & Control & VE & YC \\
\hline $\begin{array}{c}\text { Heat stress } \\
\text { period (L/h) }\end{array}$ & $74.24 \pm 2.04^{\mathrm{a}}$ & $73.50 \pm 1.98^{\mathrm{a}}$ & $74.35 \pm 1.19^{\mathrm{a}}$ \\
$\begin{array}{c}\text { Thermo-neutral } \\
\text { period (L/h) }\end{array}$ & $98.54 \pm 0.69^{\mathrm{b}}$ & $98.31 \pm 0.74^{\mathrm{b}}$ & $98.02 \pm 0.71^{\mathrm{b}}$ \\
$\begin{array}{l}\text { Whole experimenta } \\
\text { period (L/h) }\end{array}$ & $86.39 \pm 3.80^{\mathrm{b}}$ & $85.90 \pm 3.87^{\mathrm{b}}$ & $86.18 \pm 3.63^{\mathrm{b}}$ \\
$\begin{array}{l}\text { VE, vitamin E; YC, yeast culture. } \\
\mathrm{a}, \mathrm{b} \text { Means within column without a similar superscript are different } \\
(\mathrm{p}<0.05) .\end{array}$
\end{tabular}

other time spot (Table 5). The average endotoxin absorption during the whole experiment period and during HS period was the highest $(p<0.01)$ in the control and lowest $(p<0.01)$ in VE treatment, but it was not different $(p=0.161)$ among the 3 treatments during thermo-neutral period (Table 5).

\section{Antioxidants concentrations in portal vein}

Plasma concentration of SOD in portal vein in the control kept stable from 15:00 to 02:00 the next day, except for time spot (20:00), while the VE treatment kept stable before 19:00 and increased $(\mathrm{p}<0.01)$ significantly from 23:00 (Figure 4a). Plasma concentration of TAP in portal vein kept stable within each treatment, except for few prominent time spots (Figure 4b). Across treatments, plasma concentration of TAP in portal vein was the highest $(p<0.01)$ in VE and the lowest $(p<0.01)$ in the control at any time spots (Figure $4 b$ ). Plasma concentration of MDA in the portal vein of the goats kept stable across any time spots within each treatment, except for that at 21:00 (Figure 4c). Plasma MDA concentration was always the highest $(p<0.01)$ in the control and the lowest $(p<0.01)$ in VE treatment (Figure 4c).

Table 5. The average concentration of endotoxin in carotid and portal vein, and the average absorption of endotoxin in portal vein

\begin{tabular}{|c|c|c|c|}
\hline \multirow{2}{*}{ Item } & \multicolumn{3}{|c|}{ Treatments } \\
\hline & Control & VE & $\mathrm{YC}$ \\
\hline \multicolumn{4}{|c|}{ Average endotoxin concentration in carotid $(\mathrm{EU} / \mathrm{mL})$} \\
\hline Heat stress period & $0.63 \pm 0.04^{\mathrm{c}}$ & $0.43 \pm 0.02^{\mathrm{a}}$ & $0.52 \pm 0.01^{\mathrm{b}}$ \\
\hline Thermo-neutral period & $0.55 \pm 0.08$ & $0.41 \pm 0.07$ & $0.44 \pm 0.06$ \\
\hline Whole experiment period & $0.59 \pm 0.04^{\mathrm{c}}$ & $0.42 \pm 0.03^{\mathrm{a}}$ & $0.48 \pm 0.03^{\mathrm{b}}$ \\
\hline \multicolumn{4}{|c|}{ Average endotoxin concentration in portal vein $(\mathrm{EU} / \mathrm{mL})$} \\
\hline Heat stress period & $3.98 \pm 0.24^{\mathrm{c}}$ & $2.74 \pm 0.12^{\mathrm{a}}$ & $3.33 \pm 0.08^{\mathrm{b}}$ \\
\hline Thermo-neutral period & $3.53 \pm 0.50$ & $2.60 \pm 0.44$ & $2.80 \pm 0.37$ \\
\hline Whole experiment period & $3.76 \pm 0.27^{\mathrm{c}}$ & $2.67 \pm 0.22^{\mathrm{a}}$ & $3.06 \pm 0.20^{\mathrm{b}}$ \\
\hline \multicolumn{4}{|c|}{ Average absorption of endotoxin in portal vein $\left(10^{4} \mathrm{EU} / \mathrm{h}\right)$} \\
\hline Heat stress period & $24.71 \pm 0.84^{\mathrm{c}}$ & $16.86 \pm 0.39^{\mathrm{a}}$ & $20.83 \pm 0.26^{\mathrm{b}}$ \\
\hline Thermo-neutral period & $29.24 \pm 4.01$ & $21.54 \pm 3.56$ & $23.08 \pm 2.90$ \\
\hline Whole experiment period & $26.97 \pm 2.07^{\mathrm{c}}$ & $19.20 \pm 1.85^{\mathrm{a}}$ & $21.95 \pm 1.43^{\mathrm{b}}$ \\
\hline
\end{tabular}

VE, vitamin E; YC, yeast culture.

${ }^{\mathrm{a}, \mathrm{b}, \mathrm{c}}$ Means within row without a similar superscript are different $(\mathrm{p}<0.05)$. 


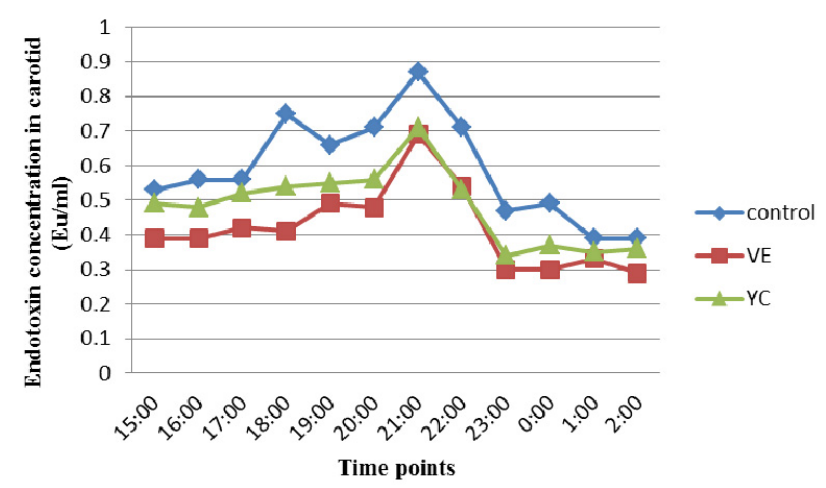

(a)

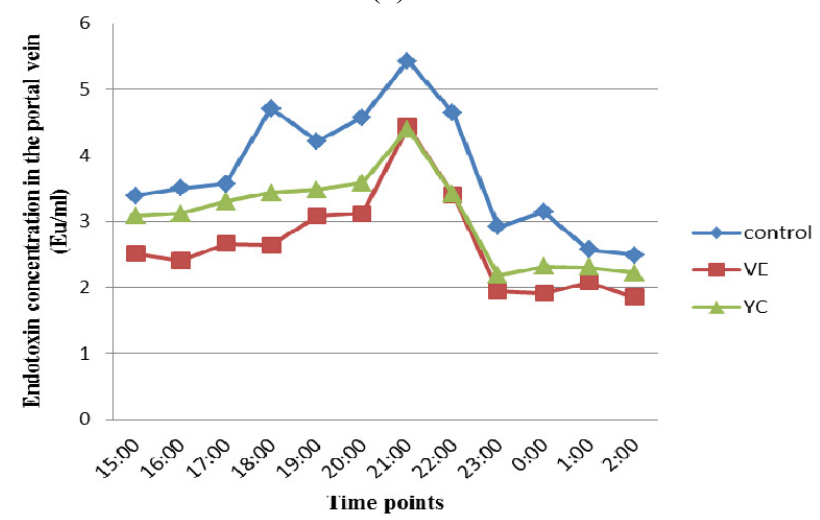

(b)

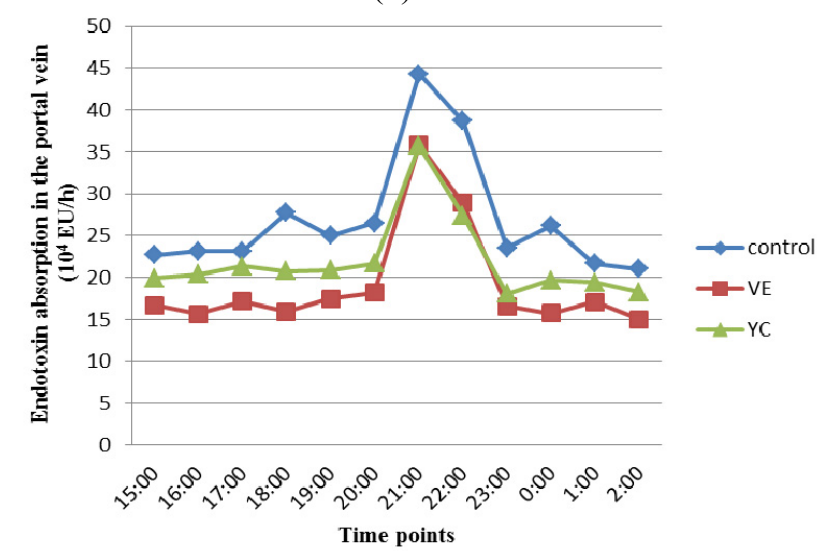

(c)

Figure 3. Endotoxin concentration in the portal vein (a) and carotid (b) and the endotoxin net absorption in the portal vein (c). VE, vitamin E; YC, yeast culture.

The average plasma concentration of TAP in portal vein was the highest $(p<0.01)$ in VE and the lowest $(p<0.01)$ in the control during HS period (Table 6). The average plasma concentration of TAP in portal vein in the control was significantly lower $(\mathrm{p}<0.05)$ than VE treatment, and the YC treatment was not significantly different from the control $(p$ $=0.06)$ and VE $(p=0.479)$ treatment during thermo-neutral period (Table 6). The average plasma concentration of TAP during the whole experiment period in the control did not differ $(p=0.089)$ from the YC treatment, but was significantly lower than VE treatment $(p<0.01)$ (Table 6).

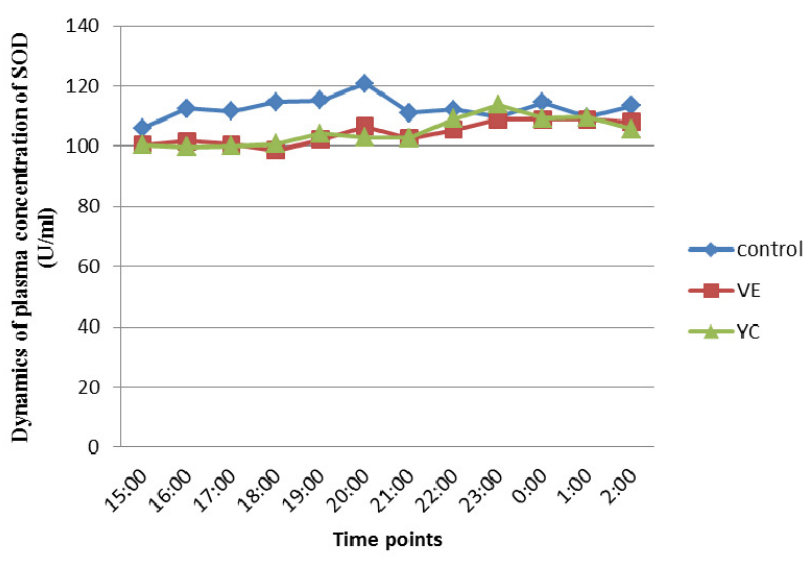

(a)

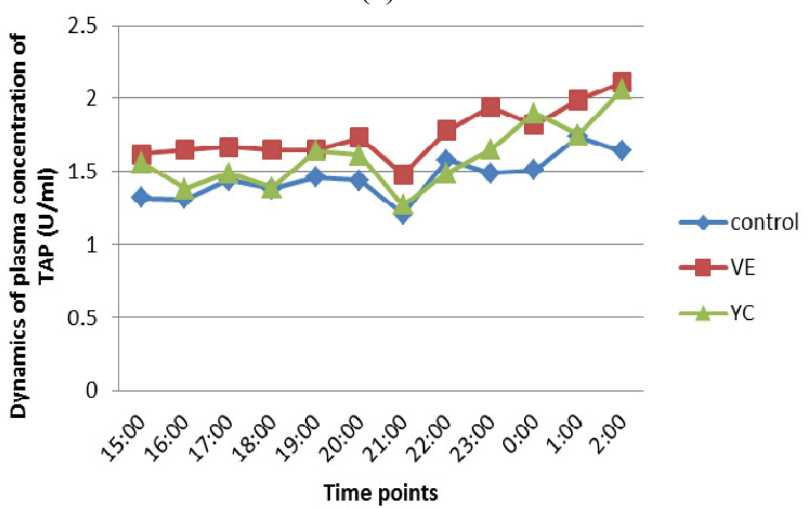

(b)

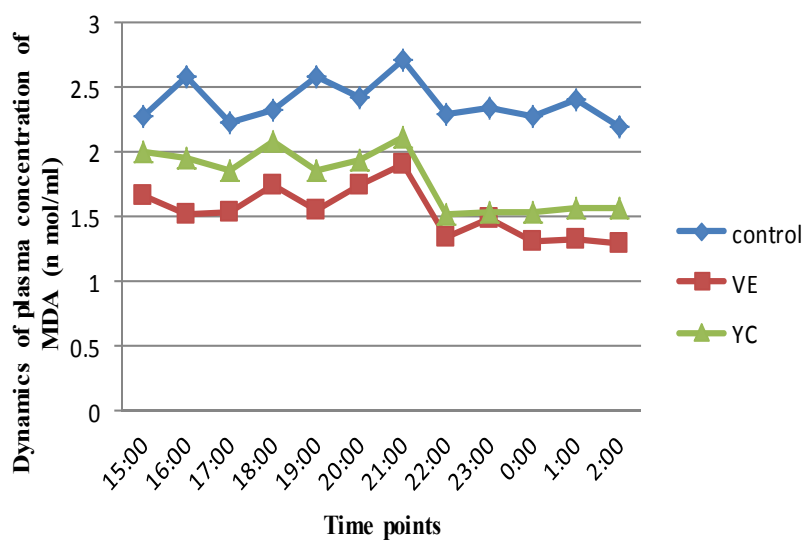

(c)

Figure 4. Dynamics of plasma concentration of superoxide dismutase (SOD, a), total antioxidant potential (TAP, b), and malonaldehyde (MDA, c) in different treatments in different time spots. VE, vitamin E; YC, yeast culture.

The average plasma concentration of SOD in VE and YC treatment during HS period was significantly lower $(p<0.01)$ than the control during HS period and whole experiment period, while no significant difference was observed between VE and YC treatments (Table 6). The SOD concentration of VE treatment was significantly lower than the control during the thermo-neutral period $(\mathrm{p}<0.01)$ (Table 6). 
Table 6. The average concentration of plasma antioxidants in different treatments

\begin{tabular}{lccc}
\hline Item & \multicolumn{1}{c}{ Treatments } & YC \\
\cline { 2 - 3 } SOD (U/mL) & Control & VE & $101.51 \pm 0.80^{\mathrm{a}}$ \\
$\quad$ Heat stress period & $113.48 \pm 1.98^{\mathrm{b}}$ & $108.36 \pm 1.53^{\mathrm{ab}}$ \\
Thermo-neutral period & $111.74 \pm 0.82^{\mathrm{b}}$ & $101.67 \pm 1.11^{\mathrm{a}}$ & $104.93 \pm 1.32^{\mathrm{a}}$ \\
Whole experiment period & $112.61 \pm 1.05^{\mathrm{b}}$ & $107.16 \pm 1.06^{\mathrm{a}}$ & $1.51 \pm 0.04^{\mathrm{b}}$ \\
TAP (EU/mL) & & $104.42 \pm 1.10^{\mathrm{a}}$ & $1.69 \pm 0.12^{\mathrm{ab}}$ \\
Heat stress period & $1.39 \pm 0.03^{\mathrm{a}}$ & $1.66 \pm 0.01^{\mathrm{c}}$ & $1.60 \pm 0.07^{\mathrm{a}}$ \\
Thermo-neutral period & $1.53 \pm 0.07^{\mathrm{a}}$ & $1.85 \pm 0.09^{\mathrm{b}}$ & $1.94 \pm 0.03^{\mathrm{b}}$ \\
Whole experiment period & $1.46 \pm 0.04^{\mathrm{a}}$ & $1.76 \pm 0.05^{\mathrm{b}}$ & $1.64 \pm 0.09^{\mathrm{ab}}$ \\
MDA (n mol/mL) & & $1.62 \pm 0.04^{\mathrm{a}}$ & $1.79 \pm 0.07^{\mathrm{b}}$ \\
Heat stress period & $2.40 \pm 0.06^{\mathrm{c}}$ & $1.44 \pm 0.10^{\mathrm{a}}$ & $1.53 \pm 0.06^{\mathrm{a}}$ \\
Thermo-neutral period & $2.37 \pm 0.08^{\mathrm{b}}$ & $2.39 \pm 0.05^{\mathrm{c}}$ &
\end{tabular}

VE, vitamin E; YC, yeast culture; SOD, superoxide dismutase; TAP, total antioxidant potential; MDA, malonaldehyde.

${ }^{a, b, c}$ Means within row without a similar superscript are different $(\mathrm{p}<0.05)$.

Plasma MDA concentration during HS period and the whole experiment period was the highest $(\mathrm{p}<0.01)$ in the control treatment, followed $(\mathrm{p}<0.01)$ by $\mathrm{YC}$ treatment, and the lowest $(\mathrm{p}<0.01)$ in VE treatment (Table 6). There was no difference $(\mathrm{p}=0.382)$ on plasma MDA concentration during thermo-neutral period between $\mathrm{VE}$ and $\mathrm{YC}$ treatments, but the VE treatment was lower $(\mathrm{p}<0.01)$ than the control treatment (Table 6).

\section{DISCUSSION}

Yeast culture and vitamin E supplementation on feed intake, rectum temperature and respiration frequency

One of the most noticeable consequences of HS is to reduce feed intake (Baumgard and Rhoads, 2012). Many studies with dairy cows (Schingoethe et al., 2004; Bruno et al., 2009; Shwartz et al., 2009) reported that YC supplementation increased feed intake during HS. Furthermore, Sahin et al. (2006) reported that VE supplementation increased feed intake of quail during HS. However, feed intake of the heat stressed dairy goats was not significantly affected by the supplementation of $\mathrm{YC}$ and VE in the present study. No study on the effect of YC and VE supplementation on feed intake of dairy goats has been previously reported.

In this study, rectum temperature and respiration frequency of goats increased during HS, which was in accordance with Darcan and Guney (2008). Researches on dairy cows revealed that the supplementation of YC (Bruno et al., 2009) and other fungal cultures (Huber et al, 1985; Gomez-Alarcon et al., 1991; Higginbotham et al., 1993) decreased rectum temperature and respiration frequency during HS. Research on poultry revealed that the high dosage of VE supplementation ( $30 \mathrm{mg} / \mathrm{kg}$ body weight) significantly decreased rectum temperature (Sinkalu et al.,
2008). In addition, Zeidan et al. (2006) reported that the injection of VE once per week (100 IU/rabbit) significantly decreased rectum temperature and respiration frequency of New Zealand rabbits. But this effect was not found in the present study on dairy goats. In present study, the VE intake of the control was above $42 \mathrm{IU} / \mathrm{d}$, and the plasma concentration of VE was $2.52 \mathrm{mg} / \mathrm{L}$. This indicated the animals VE nutrition status in the control was adequate. Although VE and YC supplementation did not decrease rectum temperature and respiration frequency of dairy goats during HS, the supplementation may help with the rehabilitation of rectum temperature and respiration frequency when ambient temperature decreased to thermoneutral zone.

\section{Yeast culture and vitamin $E$ supplementation on plasma flux rate and endotoxin absorption}

Plasma flux rate in the 3 treatments decreased with the prolonged HS, whereas it increased significantly when temperature dropped from $35^{\circ} \mathrm{C}$ to $24^{\circ} \mathrm{C}$. These results were in agreement with Kregel et al. (1988). Results from the present study showed that the supplementation of VE or YC did not significantly affect the plasma flux in portal vein of dairy goats during HS. It should be noticed that the endotoxin concentration in portal vein and carotid, and that the endotoxin absorption in portal vein in the 3 treatments increased significantly from 20:00 to 21:00 when the temperature decreased from $35^{\circ} \mathrm{C}$ to $24^{\circ} \mathrm{C}$. This could be due to the phenomenon of ischemia reperfusion injury, which refers to the functional damage of an organ caused by blood reperfusion after ischemia. The plasma flux rate in portal vein in goats during HS was $70 \mathrm{~L} / \mathrm{h}$, which was in line with Smuts et al. (1995), who reported 1,047 to 1,290 $\mathrm{mL} / \mathrm{min}$ in Alpine goats. When the temperature dropped from $35^{\circ} \mathrm{C}$ to $24^{\circ} \mathrm{C}$, blood flux rehabilitated to $100 \mathrm{~L} / \mathrm{h}$ in 
present study, an increase of more than $40 \%$. It was recently reported that the mesenteric ischemia-reperfusion induced oxidative injury of the ileum (Şen et al., 2015). The authors suspected that blood reperfusion further led to the injury of intestinal tract, and the damage of intestinal tract led to the increased permeability (Grotz et al., 1999), and this incurred the increased absorption of endotoxin. It was proven that endotoxin absorption increased during HS (Cronjé, 2005), which was not confirmed in the present study. It seemed that the average concentration of endotoxin in the portal vein and carotid of the goats was affected by dietary treatments, rather than HS. The amount of endotoxin absorption in portal vein and endotoxin concentration in portal vein and carotid was always the lowest in the VE treated and greatest in the control both in HS period and in thermo-neutral period, indicating that VE supplementation prevented endotoxin absorption.

\section{Yeast culture and vitamin $\mathbf{E}$ supplementation on plasma antioxidants}

The lowest TAP concentration and the greatest MDA concentration in the 3 treatments in the present study were attained during a narrow time slot from 20:00 to 21:00 when ambient temperature dropped from $35^{\circ} \mathrm{C}$ to $24^{\circ} \mathrm{C}$, which indicated the increased oxidative stress occurred during this period. This could also be caused by ischemia reperfusion as Horton and Walker (1993) proved that ischemia reperfusion may lead to oxidative injury.

VE supplementation significantly increased the plasma TAP concentration, while significantly decreased plasma MDA concentration of dairy goats during HS and thermoneutral periods, which meant that VE supplementation effectively strengthened the antioxidant capacity of dairy goats. VE exerts antioxidant function by breaking the free radical reaction chain (Yu, 1994). There was no report on the effect of VE supplementation on antioxidants of goat, however, a report on poultry indicated that plasma concentration of MDA decreased during HS when VE was supplemented (Sahin et al., 2006). YC supplementation only decreased plasma MDA concentration, but did not increase plasma TAP concentration during HS and thermoneutral periods, which meant that $\mathrm{YC}$ was less powerful than VE in alleviating oxidative stress. It was surprising that VE and YC supplementation lead to decreased plasma SOD concentration during HS. This was possibly attributed by the greater amount of endotoxin absorption in the control which depleted antioxidants and induced the compensatory expression of SOD gene (Ceriello et al., 1996). After $3 \mathrm{~h}$ of ischemia reperfusion, plasma SOD concentration in portal vein in VE and YC treatments, but not in the control, increased significantly. These results reflected the alleviation of oxidative stress when $\mathrm{VE}$ or $\mathrm{YC}$ was supplemented.

\section{CONCLUSION}

The portal vein plasma flux rate of heat stressed dairy goats is decreased, which leads to the increase of endotoxin absorption, and thereby decreasing the antioxidant capacity. The supplementation of VE and YC reduces the absorption of endotoxin and effectively strengthens the antioxidant capacity of dairy goats, and hence alleviates HS. Compared to $\mathrm{YC}, \mathrm{VE}$ is much more powerful in preventing endotoxin absorption and promoting antioxidant capacity.

\section{CONFLICT OF INTEREST}

We certify that there is no conflict of interest with any financial organization regarding the material discussed in the manuscript.

\section{ACKNOWLEDGMENTS}

We would like to thank the financial support provided by the Department of Sciences and Technology of Sichuan Province (2014SZ0067) and National Natural Science Foundation of China (31402104).

\section{REFERENCES}

Baumgard, L. H. and R. P. Rhoads. 2012. Ruminant Nutrition Symposium: Ruminant production and metabolic response to heat stress. J. Anim. Sci. 90:1855-1865.

Bouchama, A. and J. P. Knochel. 2002. Heat stroke. New Engl. J. Med. 346:1978-1988.

Bollengier-Lee, S., M. A. Mitchell, D. B. Utomo, P. E. V. Williams, and C. C. Whitehead. 1998. Influence of high dietary Vitamin E supplementation on egg production and plasma characteristics in hens subjected to heat stress. Br. Poult. Sci. 39:106-112.

Bollengier-Lee, S., P. E. V. Williams, and C. C. Whitehead. 1999. Optimal dietary concentration of vitamin $\mathrm{E}$ for alleviating the effect of heat stress on egg production in laying hens. Br. Poult. Sci. 40:102-107.

Bruno, R. G. B., H. M. Rutigliano, R. L. Cerri, P. H. Robinson, and J. E. P. Santos. 2009. Effect of feeding Saccharomyces cerevisiae on performance of dairy cows during summer heat stress. Anim. Feed Sci. Technol. 150:175-186.

Ceriello, A., P. dello Russo, P. Amstad, and P. Cerutti. 1996. High glucose induces antioxidant enzymes in human endothelial cells in culture: Evidence linking hyperglycemia and oxidative stress. Diabetes 45:471-477.

Cronjé, P. B. 2005. Heat stress in livestock-the role of the gut in its aetiology and a potential role for betaine in its alleviation. Recent Adv. Anim. Nutr. Australia 15:107-122.

Darcan, N. and O. Guney. 2008. Alleviation of climatic stress of dairy goats in Mediterranean climate. Small Rumin. Res. 74:212-215.

Fan, L., L. Hu, B. Yang, X. Fang, Z. Gao, W. Li, Y. Sun, Y. Shen, X. Wu, Y. Shu, Y. Gu, X. Wu, and Q. Xu. 2014. Erlotinib 
promotes endoplasmic reticulum stress-mediated injury in the intestinal epithelium. Toxicol. Appl. Pharmcol. 278:45-52.

Flanagan, S. W., P. L. Moseley, and G. R. Buettner. 1998. Increased flux of free radicals in cells subjected to hyperthermia: Detection by electron paramagnetic resonance spin trapping. FEBS Lett. 431:285-286.

Gathiram, P., M. T. Wells, J. G. Brock-Utne, and S. L. Gaffin. 1987. Antilipopolysaccharide improves survival in primates subjected to heat stroke. Circ. Shock 23:157-164.

Gomez-Alarcon, R. A., J. T. Huber, G. E. Higginbotham, F. Wiersma, D. Ammon, and B. Taylor. 1991. Influence of feeding Aspergillus oryzae fermentation extract on the milk yields, eating patterns, and body temperatures of lactating cows. J. Anim. Sci. 69:1733-1740.

Grotz, M. R., E. A. Deitch, J. Ding, D. Xu, Q. Huang, and G. Regel. 1999. Intestinal cytokine response after gut ischemia: Role of gut barrier failure. Ann. Surg. 229:478-486.

Hall, D. M., G. R. Buettner, L. W. Oberley, L. Xu, R. D. Matthes, and C. V. Gisolfi. 2001. Mechanisms of circulatory and intestinal barrier dysfunction during whole body hyperthermia. Am. J. Physiol. Heart Circ. Physiol. 280:H509-H521.

Harmon, R. J., M. Lu, D. S. Trammel, and B. A. Smith. 1997. Influence of heat stress and calving on antioxidant activity in bovine blood. J. Dairy Sci. 80(Suppl. 1):264.

Higginbotham, G. E., D. L. Bath, and L. J. Butler. 1993. Effect of feeding an Aspergillus oryzae extract on milk production and related responses in a commercial dairy herd. J. Dairy Sci. 76: 1484-1489.

Horton, J. W. and P. B. Walker. 1993. Oxygen radicals, lipid peroxidation, and permeability changes after intestinal ischemia and reperfusion. J. Appl. Physiol. 74:1515-1520.

Huber, J. T. 1998. Yeast products help cattle handle heat. Hoard's Dairyman 143:367.

Huber, J., G. Higginbotham, and D. Ware. 1985. Influence of feeding Vitaferm, containing an enzyme-producing culture from Aspergillus oryzae, on performance of lactating cows. J. Dairy Sci. 68(Suppl):122(Abstr.).

Huntington, G. B., C. K. Reynolds, and B. H. Stroud. 1989. Techniques for measuring blood flow in splanchnic tissues of cattle. J. Dairy Sci. 72:1583-1595.

Huntington, G. B. 1982. Portal blood flow and net absorption of ammonia-nitrogen, urea-nitrogen, and glucose in nonlactating Holstein cows. J. Dairy Sci. 65:1155-1162.

Kregel, K. C., P. T. Wall, and C. V. Gisolfi. 1988. Peripheral vascular responses to hyperthermia in the rat. J. Appl. Physiol. 64:2582-2588.

Mani, V., T. E. Weber, L. H. Baumgard, and N. K. Gabler. 2012. Growth and Development Symposium: Endotoxin, inflammation, and intestinal function in livestock. J. Anim. Sci. 90:1452-1465.
Marai, I. F. M., A. A. El-Darawany, A. Fadiel, and M. A. M. Abdel-Hafez. 2007. Physiological traits as affected by heat stress in sheep-A review. Small Rumin. Res. 71:1-12.

Pan, P. J., C. F. Hsu, J. J. Tsai, and J. H. Chiu. 2012. Musculoskeletal: The role of oxidative stress response revealed in preconditioning heat stimulation in skeletal muscle of rats. J. Surg. Res. 176:108-113.

Sahin, K., M. Onderci, N. Sahin, F. Gulcu, N. Yıldız, M. Avcı, and O. Kucuk. 2006. Responses of quail to dietary vitamin $\mathrm{E}$ and zinc picolinate at different environmental temperatures. Anim. Feed Sci. Technol. 129:39-48.

Saxton, A. M. 1998. A macro for converting mean separation output to letter groupings in PROC MIXED. In Proc. 23rd SAS User Group Intl. SAS Institute, Cary, NC, USA. pp. 1243-1246.

SAS Institute. 2009. User's Guide: Statistics. 9th ed. SAS Inst. Inc., Cary, NC, USA.

Schingoethe, D. J., K. N. Linke, K. F. Kalscheur, A. R. Hippen, D. R. Rennich, and I. Yoon. 2004. Feed efficiency of midlactation dairy cows fed yeast culture during summer. J. Dairy Sci. 87:4178-4181.

Şen, L. S., B. Karakoyun, C. Yeğen, M. Akkiprik, M. Yüksel, F. Ercan, A. Özer, and B. Ç. Yeğen. 2015. Treatment with either obestatin or ghrelin attenuates mesenteric ischemiareperfusion-induced oxidative injury of the ileum and the remote organ lung. Peptides 71:8-19.

Shwartz, G., M. L. Rhoads, M. J. Van Baale, R. P. Rhoads, and L. H. Baumgard. 2009. Effects of a supplemental yeast culture on heat-stressed lactating Holstein cows. J. Dairy Sci. 92:935-942.

Sinkalu, V. O., J. O. Ayo, A. B. Adelaiye, and J. O. Hambolu. 2008. Effects of vitamin $\mathrm{E}$ on diurnal variation in rectal temperature of Black Harco pullets during the hot-dry season. J. Therm. Biol. 33:32-36

Smuts, M., S. G. Pierzynowski, R. Puchala, A. Al-Dehneh, T. Sahlu, J. M. Fernandez, and R. N. Heitmann. 1995. Effect of mimosine on portal-drained visceral net flux and concentrations of amino acids and minerals in plasma of Alpine goats. Small Rumin. Res. 18:43-49.

Wang, L., B. Xue, K. Wang, S. Li, and Z. Li. 2011. Effect of heat stress on endotoxin flux across mesenteric-drained and portaldrained viscera of dairy goat. J. Anim. Physiol. Anim. Nutr. 95:468-477.

Yokota, M., J. Kambayashi, T. Tanaka, T. Tsujinaka, M. Sakon, and T. Mori. 1989. A simple turbidimetric time assay of the endotoxin in plasma. J. Biochem. Biophys. Methods 18:97-104.

Yu, B. P. 1994. Celluler defenses against damage from reactive oxgen species. Physiol. Rev. 74:139-162.

Zeidan, A. E. B., G. M. A. Solouma, M. H. El Nenaey, M. S. Shoeib, and M. M. El Taher. 2006. Reproductive activity of heat stressed rabbit bucks and its improvement using vitamin $\mathrm{E}$ and selenium under subtropical Egyptian condition. Assiut Vet. Med. J. 52:360-382. 